$\xi=2$ 줄

\title{
Nano - maxillofacial surgery: development which cannot be avoided
}

\author{
Abhishek P.T ${ }^{1 *}$, RadhikaPethkar ${ }^{1}$, SarinNizar $^{1}$, Kishore Felix $^{2}$, NeethiDalvi ${ }^{3}$ \\ ${ }^{I}$ Department of Oral and maxillofacial surgeryKVGDC and Hospital, Sullia, Dakshina Karnataka Dist, Karnataka, India \\ ${ }^{2}$ Department of Oral and maxillofacial surgery, Rajarajeswari Dental college and hospital, Bangalore, India \\ ${ }^{3}$ DDS, NYU Of Dental College, New York, NY 10003, United States of America \\ *Corresponding author E-mail:abhishekmaxfacs@gmail.com
}

\begin{abstract}
Objective:

1) To understand the importance of nanotechnology in maxillofacial surgery.

2) To impress the importance of adaptingnanotechnology in making the surgeries and diagnosis easy and more effective.

Design: Various databases, including MEDLINE and EMBASE, were searchedto identify published articles related to nanotechnology and dentistry as well as in maxillofacial surgery. An exhaustive search was conducted and four reviewers independently completed inclusion assessment, data extraction, and risk of bias assessment for all studies identified.

Conclusion: The review foundlittle evidence ofany recent research papers conducted aboutnanotechnology in dentistry or maxillofacial surgery. However, our study stress upon the need ofthe health care professionals like dental surgeons, specially oral and maxillofacial surgeons to be aware of the importance ofadapting new trends in nanotechnology.

Maxillofacial surgeons need to takemore efforts and the supporting associations or societies need to provide more resources in the field of research to help the oral and maxillofacial surgeons be at par with the advanced world of nanotechnology and nanosurgery.
\end{abstract}

Keywords:Nano-maxillofacial surgery; Nano-surgery; Robotics; Nano diagnosis; Nano technology.

\section{Introduction}

Science and technology is presently undergoing a great evolution and today we are living in an era of nanotechnology (Ashley $\mathrm{S}$ 2001, p.76).

"Nano" is the Greek word for 'dwarf'.Nanotechnology is the science of converting matter measured in the billionths of meters (nanometer), maximum in the size of two or threeatoms (Saravana KR \&Vijayalakshmi R. , p.62).

Technology has undergone another change, in the size of atoms which is approximately as small as $0.1 \mathrm{~nm}$. Considering that the size of a useful nanostructure is 1 to $100 \mathrm{~nm}$, it is clearly seen that the area of nanotechnology works at the level of atoms and molecules." (Erkoç Ş \&Nanobilim 2007, p.1).

The late Nobel Prize winning scientist Richard P. Feynman in 1959 put forward the very first practical achievement of nano devices as early as 1959 . His speech titled "There is plenty of room at the bottom." which concluded on a note that "this is a development which I think cannot be avoided." (Feynman R \&Freitas RA 1959, p.282).

Nanotechnology can be translated as "the science of the small." (Duke ES 2003, p.380). It is a huge paradigm shift for all of us whose smallest measurement till date was a millimetre. In terms of nanotechnology one millimetre is equal to 100000 nano meter.

In coming future, dentistry may soon be influenced by nanotechnology in the field of most advanced diagnostics and prevention, drug delivery and gene therapy. (RudraPratap 2003, p.675).

The changes that which nano technology has brought right from our daily life to advanced nuclear-war fields is very much obvious. So as a distinguished speciality of dentistry, oral and maxillofacial surgery which is considered as a bridge between medicine and dentistry cannot turn away from accepting this fast development of this era. Today by moulding ourselves according to the changes, drastic progress have happened in the field, starting fromthe administration of local anaesthesia to the wide variety of treatment modalities for oral cancer.(Freitas RA Jr 1999, p.345, Bachmann G 2000, p. 233).

\section{Nano-surgery}

\subsection{Robotics in dentistry and robotic surgeries}

It was Freitas Ra has discussed the idea of nano robots or dentirobots in dentistry more than a decade ago in 2000. Till then role of robotics was restricted only to diagnosis. This was achieved by the nano robot functions which were preset and controlled by another onboardnano computer where all executions of the robots were already programmed. (Freitas RA Jr 2000, p-1559)

\subsection{Nano - induction of local drug delivery in oral cavi- ty}

Recent studies have shown that, a micro exposing spot of dentinal tubules which creates hypersensitivity has been successfully blocked by nano sized carbonate appetite. (Lee SY et al 2008, p.847)

Nano-robotic analgesics are an excellent modality to provide comfort to the patient. Same way researches are being done to analyse and study the effect of nano induction of local drug delivery in maxillofacial region. A procedure called Arestin ${ }^{\circledR}$, in which microspheres of tetracycline are deposited into periodontal pockets and tetracycline is administered locally and concluded nano drug 
delivery and controlling its local action is possible in very near future. (Kong LX et al 2000, p.184)

\subsection{Nano - diagnosis and treatment in maxillofacial on- cology}

i) Nanodiagnostic techniques based NEMS (Nano Electromechanical Systems)

Nanodiagnostic techniques based NEMS biosensors which gives excellent diagnostic result about minute tissue changes, down to single molecule level are being developed. Basic principle behind the NEMS is converting bio chemical changes to electrical signal (Gau V \& Wong D 2007, p.401).

Likewise, multiplexing modality works by Sensing large numbers of different biomolecules nerve traffic, simultaneously in real time.

ii) Optical nano-biosensor

C-reactive protein which is proved out to be a clear indicator of tissue response in human body can be identified quickly by optical nano-biosensor. The nano-biosensor is a unique fibre optics-based tool which allows the minimally invasive diagnosis. (Whitesides GM \& Love JC 2001, p.33).

iii) Oral fluid nano-sensor test (OFNASET)

Saliva is known as an indicator for so many diseases of human body. So detecting the change in salivary bookmarkers helps in the oral cancer detection early as possible.

Two salivary proteomic biomarkers

a) Thioredoxin and

b) IL-8

Four salivary mRNA biomarkers

a) SAT,

b) ODZ

c) IL-8,

d) IL-1bcan detect oral cancer with amazingly accurate specificity and sensitivity.

(Freitas RA Jr 2000,p-1559,Whitesides GM \& Love JC 2001, p.33,Li Y et al 2005,p.3)

iv) Treatment

Nanotechnology has improved the treatment modalities and outcome ofmaxillofacial tumours and other malignant disease. Brachytherapy done by using nanomaterials like BrachySilTM (Sivida, Australia) delivers 32P said to be on its clinical trials. For extensive tumours involving brain, drug delivery crossing the blood brain barrier is bringing positive results (Suh JY et al 2007,p.362).

\subsection{Nano - bone replacement materials}

Recent studies shows nanohydroxyapatitebone crystals are found to be more effective than any other type of bone replacements.

\subsection{Nano technology and dental implants}

First and important thing for implant success is osteosynthesis around the implant. Recent studies done in tibia of rabbit shows nanostructured calcium coated implants gives good and faster response in the bone formation around the implant. (Suh JY et al 2007, p.362, Braceras I 2009, p.274)

It is said that roughening of the implant surface plane by nanosized particles enhances cellular response that exhibits in the tissues.

\section{Conclusion}

Research is a vast arena. It is the stepping stone to every discovery. Maxillofacial surgeons need to takemore efforts and the supporting associations and societies need to provide more resources in the field of research to help the oral and maxillofacial surgeons to be at par with the advanced world of nanotechnology and nano- surgery. Be it stem cell research, tissue engineering or nanotechnology, we need to strive to be better than what we are today.

The fascinating fact about science is that it is ever changing and ever evolving. As described earlier, nanotechnology is an epitome of one such change. Times are good for the field of dentistry and more so for the field of maxillofacial surgery. But the question is, are we ready for it? Let's adjust our sails so that when finally the winds of nano-maxillofacial surgery blow we are in a position to take full advantage of this development or maxillofacial surgeons all over especially those from the still developing countries like Indiamay miss out on the opportunities which matter.

\section{References}

[1] Ashley S: Nanobot Construction Crews, Scientific Definitions, Clinical Chemistry, 40(9): 1797-American, 285(3): 76-77, 2001.

[2] Saravana KR, Vijayalakshmi R. Nanotechnology in dentistry. Ind J Dent Res. 2006; 17:62-65.https://doi.org/10.4103/0970-9290.29890.

[3] Erkoç Ş. NanobilimveNanoteknoloji. 1. Bask1, Ankara: ODTÜ Yayıncılık; 2007. pp. 1-10.

[4] Feynman R, Freitas RA Jr: Nanodentistry, Journal of the In: Gilbert HD (Ed.), Miniaturization, New York: American Dental Association, 131(11):1959Reinhold, 282-296.

[5] Duke ES. Has dentistry moved into the nanotechnology era? CompendContinEduc Dent. 2003; 24:380-382.

[6] RudraPratap: Engaging Private Enterprise in Nanomedicine, Volume I: Basic Nanotech Research in India: ICS, Trieste, Capabilities, Georgetown, TX: Landes February, 675-680.

[7] Freitas RA Jr: Nanomedicine, Volume I: Basic Nanotech Research in India: ICS, Trieste, Capabilities, Georgetown, TX: Landes February, 675-680, 2005. Bioscience, 345-350, 1999.

[8] Bachmann G:Innovationsschubausdem 2000 http://www.wired.com/wired/archive/8.04/ Nanokosmos, Technologieanalyse. Düsseldorf: joy.html VDI-Technologiezentrum, 233245.

[9] Freitas RA Jr, Nanodentistry. J Am Dent Assoc. 2000; 131:15591565. 10) Lee SY, Kwon HK, Kim BI. Effect of dentinal tubule occlusion by dentifrice containing nano-carbonate apatite. J Oral Rehabil. 2008; 35:847-853. https://doi.org/10.1111/j.13652842.2008.01876.x.

[10] Kong LX, Peng Z, Li SD, Bartold M. Nanotechnology and its role in the management of periodontal diseases. Periodontol 2000. 2006; 40:184-196. https://doi.org/10.1111/j.1600-0757.2005.00143.x.

[11] Gau V, Wong D. Oral fluid nanosensor test (OFNASET) with advanced electrochemical-based molecular analysis platform. Ann NY AcadSci 2007; 1098:401-10. https://doi.org/10.1196/annals.1384.005.

[12] Whitesides GM and Love JC: The Art of Building Small, Scientific American,285(3):33-41,2001. https://doi.org/10.1038/scientificamerican0901-38.

[13] Li Y, Denny P, Ho CM. The Oral Fluid MEMS/NEMS Chip (OFMNC): Diagnostic and Translational Applications. Adv Dent Res 2005; 18:3-5. https://doi.org/10.1177/154407370501800102.

[14] Suh JY, Jeung OC, Choi BJ, Park JW. Effects of a novel calcium titanate coating on the osseointegration of blasted endosseous implants in rabbit tibiae. Clin Oral Impl Res. 2007; 18:362369.https://doi.org/10.1111/j.1600-0501.2006.01323.x.

[15] Braceras I, De Maeztu MA, Alava JI, Gay-Escoda C. In vivo lowdensity bone apposition on different implant surface materials. Int $\mathrm{J}$ Oral Maxillofac Surg. 2009; 38:274278.https://doi.org/10.1016/j.ijom.2008.12.016 